\title{
SituACión DE LAS ADMinistraCiOnES ADUANERAS EN HONDURAS DURANTE LA PANDEMIA COVID-I9
}

\author{
Sindy Stephany Discua López*
}

DOI: I0.5377/EYA.VIIII.IO5I2

Recibido: 21/05/2020 Aceptado: $18 / 08 / 2020$

\section{RESUMEN}

La administración aduanera es un campo muy importante que ha venido a garantizar el abastecimiento de los insumos necesarios para todas las familias del país. Priorizar y agilizar el comercio de todo lo necesario ha sido el lema desde la Organización Mundial de Aduanas (OMA) hasta cada una de las administraciones aduaneras de los países. La pandemia nos mantiene confinados a algunos en nuestros hogares y a otros luchando para garantizar la salud, la seguridad y el abastecimiento de suministros. En Honduras existen 8 terminales portuarias 4 aéreas y 11 terrestres entre aduanas pasos fronterizos y guardaturas; es necesario que el país cuente en cada una de ellas y en cada lugar que se realice una gestión aduanera con todas las medidas de bioseguridad que garanticen la salud e higiene. Como en todas las instituciones y empresas los procesos logísticos en aduanas deben proporcionar en primera instancia la seguridad e higiene de todas las áreas, especialmente de sus colaboradores. Por lo que, esta investigación tiene el objetivo de indagar la forma en cómo se ha estado manteniendo la seguridad de la salud de los colaboradores y la garantía de la realización de los procesos aduaneros.

PALABRAS CLAVE: administración de aduanas, COVID-19, OMA, Honduras.

JEL: F13 *Profesora investigadora del Departamento de Administración Aduanera, Universidad Nacional Autónoma de Honduras. https://orcid.
org/0000-0003-2943-5246 Correo electrónico: sindy.discua@unah.edu.hn Tegucigalpa, Honduras. 


\title{
Situation of CUSTOMS ADMinistrations in HONDURAS DURING THE COVID-I9 PANDEMIC
}

\author{
Sindy Stephany Discua López*
}

DOI: I0.5377/EYA.VIIII.IO5I2

Received: $21 / 05 / 2020$

Accepted: 18/08/2020

\begin{abstract}
The customs administration is a very important field, which has come to guarantee the supply of the necessary supplies for all the families in the country. Prioritizing and streamlining the trade of everything necessary has been the motto, from the World Customs Organization (WCO), to each of the countries' customs administrations. The pandemic keeps some of us confined to our homes and others struggling to ensure health, safety, and the supply of supplies. In Honduras there are 8 port terminals, 4 air and 11 land terminals in the country, between customs, border crossings and guards; It is necessary that the country has in each one of them and in each place that customs management is carried out, with all the biosecurity measures that guarantee health and hygiene. As in all institutions and companies, customs logistics processes must provide, in the first instance, the safety and hygiene of all areas, especially their collaborators. Therefore, this research has the objective of investigating the way in which the health security of the collaborators has been maintained and the guarantee of carrying out the customs processes
\end{abstract}

KEYWORDS: customs administration, COVID-19. OMA, Honduras.

JEL: F13

**Research professor at the Customs Administration Department, National Autonomous University of Honduras. https://orcid.org/00000003-2943-5246 Email: sindy.discua@unah.edu.hn Tegucigalpa, Honduras. 


\section{INTRODUCCIÓN}

Fue el 07 de enero del 2020 que el mundo informa que en el oriente (China) se ha identificado un virus inicialmente llamado 2019-nCov; causando su primera muerte el 09 de enero de ese mismo año. Mientras el mundo ya se encontraba agobiado, ante los incendios forestales de Australia y la amenaza de una tercera guerra mundial en donde parecía que el mes enero no terminaba.

Mientras que China luchaba internamente con el nuevo virus suspendiendo tours tanto nacionales como internacionales; enero culminaría con la declaración de emergencia internacional de salud pública anunciada por la Organización Mundial de la Salud conocida por sus siglas como OMS.

El mundo entero desde ese momento y hasta entonces generaba "humor" creaba teorías de la supuesta procedencia del virus y se encontraba incrédulo ante esta situación; mientras que cientos de personas morían. Registrando más de 500 muertes a nivel global el 05 de febrero y superando las 2000 a tan solo 13 días después (CNN en Español, 2020).

Honduras se encontraba como la mayoría de los países a la expectativa y al mismo tiempo indiferente a este virus, fue hasta el 10 de marzo que el país recibe la noticia en donde una hondureña residente en España muere a consecuencia del ahora conocido como COVID-19. En esos días el Gobierno pretendía preparar al país ante la inminente llegada del virus a Honduras. Sin embargo, el 11 de marzo en el país registra el primer caso de COVID-19 tratándose de una mujer que había ingresado al país el 04 de marzo proveniente de España; mismo día en el que la OMS declara la enfermedad como una pandemia.

La Universidad Nacional Autónoma de Honduras (UNAH) anuncia la suspensión de labores a partir del 11 de marzo y todo tipo de actividad programada, en un inicio se pretendía solamente evitar las actividades que requerían de la aglomeración de más de 50 personas. Pero el 16 de marzo el Gobierno de Honduras decreta toque de queda ante la alerta y a partir del 20 de marzo declara toque de queda absoluto para los lugares más afectados; autorizando a comercios necesarios las entregas de sus productos a domicilio permitiendo a la población abastecerse de los insumos básicos. Las medidas fueron aumentando y hasta el momento el abastecimiento se realiza de acuerdo con último número de la tarjeta de identidad de las personas.

Para lograr el abastecimiento de insumos básicos, algunos servicios no podían dejar de ofrecerse al público; entre ellos encontramos el que ofrecen las aduanas del país, recordando que las actividades de entrada de productos nunca cesaron ante la emergencia, por lo que en ningún momento las aduanas dejaron de funcionar.

\section{MARCo REFERENCIAL}

Desde la declaración de emergencia internacional de salud pública se esperó que el movimiento de bienes de socorro (suministros, medicamentos y equipos, etc.) a través de las fronteras aumentará dramáticamente. Igualmente es necesario asegurar que ninguna familia sufra de hambre ni durante el COVID-19 ni después de él.

\subsection{La Organización Mundial de Aduanas y el COVID-19}

E1 Secretario General de la Organización Mundial de Aduanas (OMA) el Dr. Kunio Mikuriya invitó a la comunidad aduanera mundial a continuar abogando y realizar la facilitación no sólo de suministros de socorro, sino, de todos los bienes que se comercializan para minimizar el impacto de la pandemia COVID-19 expresando que aunque se presenciaba una situación sin precedentes, estaba seguro de que actuando juntos, con un espíritu de solidaridad, se podría mitigar los efectos de la pandemia de COVID-19 en nuestras sociedades y economías. Para lo cual, se puso a disposición de los aduaneros una página que presenta las actualizaciones con material de orientación, las mejores prácticas de los Miembros y una base de datos de puntos de contacto de las administraciones de aduanas, esta última, accesible solo para los Miembros. Igualmente, se designaron personas de contacto que puedan atender consultas sobre los procedimientos 
aplicables para la importación, exportación y tránsito de envíos de socorro, y equipos para fines humanitarios por vía aérea, terrestre y marítima (World Customs Organizations, 2020).

La OMA no solamente pretende agilizar el comercio de suministros de socorro sino asegurar la continuidad de toda la cadena de suministros hasta entonces no se tiene ninguna situación en donde se establezca que las mercancías en importación o exportación sean foco de infección. A través de un comunicado del 23 de marzo del 2020 la OMA advierte sobre la existencia de suministros médicos falsificados que están siendo comercializados a través de páginas web u otro medio en línea, sabemos que ante cualquier situación siempre existen personas que se aprovechan de las necesidades. Por lo que, la Organización instruye a crear mecanismos de control de exportación de equipos de protección personal. Se han dado para ello incautaciones de equipos tales como mascarillas y desinfectante de mano falsificados, animando a mantener todas las medidas de control y vigilancia ante estos tiempos difíciles. Siendo un dato importante para el país debido a que Honduras realiza la importación de estos equipos.

Para combatir esta inoportuna situación creada por las organizaciones delictivas la OMA lanza el Grupo CENcomm de Derechos de Propiedad Intelectual (DPI) en la plataforma CENcomm 3.0 recientemente modernizada. Es un sistema de comunicación basado en la web, permite a un grupo cerrado de usuarios de funcionarios de aduanas intercambiar información de inteligencia, mensajes y alertas a través de canales seguros. Este intercambio de información potencia y mejora las operaciones de aplicación y gestión de riesgos de las administraciones participantes en las áreas de lucha contra las infracciones de los DPI y la capacidad de seguridad de los consumidores (World Customs Organization, 2020).

\subsubsection{Declaraciones conjuntas}

La Organización Mundial de Aduanas (OMA) y la Organización Mundial del Comercio (OMC) han tenido siempre como objetivo primordial realizar la facilitación del comercio y en esta ocasión no se han quedado atrás y se han comprometido para trabajar conjuntamente para facilitar el comercio de bienes esenciales como suministros médicos, alimentos y energía. Igualmente, desean trabajar de forma coordinada en todas aquellas ideas que permitan la facilitación en el comercio transfronterizo para que los bienes esenciales puedan llegar rápidamente a los más necesitados, incluidos los países menos desarrollados y sin litoral (World Customs Organization, 2020).

La OMA igualmente ha realizado otras declaraciones conjuntas con respecto al COVID-19 y la facilitación del comercio, tal es el caso de la Organización Marítima Internacional (OMI), donde establecen que la comunicación, coordinación y cooperación tanto a nivel nacional como local, entre barcos, instalaciones portuarias, administraciones aduaneras y otras autoridades competentes son de suma importancia para garantizar el flujo seguro y fácil de suministros y equipos médicos vitales, productos agrícolas críticos, y otros bienes y servicios transfronterizos. Trabajar para resolver las interrupciones en las cadenas de suministro mundiales para apoyar la salud y el bienestar de todas las personas la OMI ha publicado la siguiente serie de Cartas circulares que abordan cuestiones globales relevantes para la gente de mar y la industria del transporte marítimo en el contexto del brote de COVID-19:

- Carta Circular No 4204 del 31 de enero de 2020 que proporciona información y orientación sobre las precauciones que deben tomarse para minimizar los riesgos para la gente de mar, los pasajeros y otras personas a bordo de los buques del nuevo coronavirus (COVID-19),

- Carta Circular No 4204 / Add.1 de 19 de febrero de 2020, COVID-19 - implementación y aplicación de los instrumentos pertinentes de la OMI,

- Carta Circular No 4204 / Add.2 de 21 de febrero de 2020, declaración conjunta OMI-OMS sobre la respuesta al brote de COVID-19,

- Carta Circular No 4204 / Add.3 de 2 de marzo de 2020, consideraciones operativas para la gestión de casos / brotes de COVID-19 a bordo de buques preparados por la OMS, 
- Carta Circular No 4204 / Add.4 de 5 de marzo de 2020, ICS coronavirus (COVID-19) orientación para los operadores de buques para la protección de la salud de la gente de mar,

- Carta circular No 4204 / Add.5 / Rev.1 de 2 de abril de 2020, coronavirus (COVID-19) Orientaciones relativas a la certificación de la gente de mar y el personal de los buques pesqueros,

- Carta circular No 4204 / Add.6 de 27 de marzo de 2020, coronavirus (COVID-19) - Lista preliminar de recomendaciones para gobiernos y autoridades nacionales relevantes sobre la facilitación del comercio marítimo durante la pandemia de COVID-19, y

- Carta Circular No 4204 / Add.7 de 3 de abril de 2020, coronavirus (COVID-19) - Orientación sobre retrasos imprevistos en la entrega de buques.

Igualmente, el 15 de abril del presente año la Unión Postal Universal (UPU) enviaron una carta conjunta para informar a sus respectivos miembros de las acciones tomadas por la OMA y la UPU en respuesta al brote de COVID-19, enfatizando que la coordinación entre las administraciones aduaneras y los operadores postales designados es fundamental para la facilitación continua de la cadena de suministro postal global y para mitigar el impacto general del brote en nuestras sociedades. La UPU ha publicado mensajes debido a la interrupción de la cadena de suministro postal a nivel internacional y ha propuesto nuevas herramientas para consolidar soluciones (World Customs Organization, 2020).

E1 11 de mayo se realiza otra declaración conjunta con la Unión Internacional de Transporte por Carretera (URI), que en respuesta ante la pandemia piden conjuntamente a las administraciones de aduanas de todo el mundo que:

- Garantizar intervenciones transfronterizas coordinadas en cooperación con otros organismos fronterizos nacionales $y$ aplicar normas internacionales como el Convenio TIR (del francés Transit International Routier o Transport International Routier), según proceda,

- Utilizar el sistema TIR y sus herramientas informáticas, siempre que sea posible, que permiten un transporte seguro bajo control aduanero con controles físicos limitados y menos contacto entre las personas en las fronteras, reduciendo así el riesgo de propagación del virus $\mathrm{y}$ protegiendo a los funcionarios y conductores de aduanas,

- Designar carriles prioritarios (verdes) para los vehículos comerciales para reducir los tiempos de espera fronterizos e introducir otras medidas para garantizar la continuidad de la cadena de suministro,

- Evitar el cierre de las fronteras al transporte internacional de mercancías, en particular para las mercancías de socorro, el personal y las mercancías esenciales, $y$

- Evite la comprobación innecesaria de vehículos comerciales en las fronteras.

El 15 de mayo la Organización Intergubernamental para el Transporte Internacional por Ferrocarril (OTIF) y la Organización para la Cooperación entre Ferrocarriles (OSJD), declaran conjuntamente que como resultado del impacto de COVID-19 en la industria ferroviaria, algunas compañías ferroviarias enfrentan desafíos en la preparación y recopilación de documentos en papel necesarios para los procedimientos aduaneros en el transporte ferroviario internacional. En este contexto, se alienta a las administraciones aduaneras a facilitar el transporte ferroviario al aceptar temporalmente documentos electrónicos y diferir el requisito de documentos en papel hasta una etapa posterior, si es necesario, según lo estipulado en el Convenio de Kyoto Revisado de la OMA.

\subsubsection{Instrumentos y herramient as contra el COVID-19}

La OMA crea igualmente una sección en su sitio web que incluye los siguientes instrumentos $y$ herramientas existentes y recientemente desarrolladas relevantes para la integridad y la facilitación de la cadena de suministro en el contexto de la pandemia de COVID-19.

Este existe con la finalidad que todos los países 
miembros compartan sus mejores prácticas ante la situación de emergencia. En esta sección encontramos: (1) noticias importantes (que versan sobre la situación actual del virus y el comercio), (2) la comunicación de la OMA y los socios sobre el COVID-19, (3) instrumentos y herramientas de la OMA, (4) las prácticas de los miembros en respuesta a la pandemia del COVID-19, (5) estado de los puntos de entrada e información publicada por organizaciones asociadas, (6) recomendaciones y orientaciones de la OMS.

Dentro de esta sección encontramos todos los comunicados realizados por la OMA y una lista de referencias de clasificación HS para suministros médicos relacionados con COVID-19: http://www. wcoomd.org/-/media/wco/public/global/pdf/topics/ nomenclature/covid_19/hs-classification-reference en.pdf?la=en. Igualmente se proporciona una lista de clasificación para medicamentos prioritarios: https://www.who.int/emergencies/diseases/novelcoronavirus-2019/technical-guidance/covid-19critical-items.

E1 24 de abril la secretaría de la OMA compartió las orientaciones con las aduanas sobre estrategias de comunicación eficiente durante una crisis con el fin de ayudar a los miembros de reaccionar ante los desafíos de comunicación que se presentan ante la pandemia. El Secretario General de la OMA, Dr. Kunio Mikuriya aconseja que "las administraciones aduaneras deben instruir, informar, fomentar comportamientos de autoprotección, actualizar la información sobre riesgos, generar confianza en los funcionarios y disipar rumores garantizando al mismo tiempo la integridad y la facilitación continua de la cadena de suministro mundial". Se concluye que, aunque no se puede controlar a nivel de salud la propagación del virus aún se puede controlar la forma de comunicación entre las partes para lo cual están abiertos a recibir todas las ideas para hacerlo posible.

Al 19 de mayo la OMA se ha asociado con las partes interesadas para poner en marcha todo el repositorio de recomendaciones y buenas prácticas para facilitar el comercio ante la crisis de salud que se vive. La OMA se ha asociado con la OMC, la Conferencia de las Naciones Unidas sobre Comercio y Desarrollo (UNCTAD), la Oficina de los Pequeños Estados de la Mancomunidad (conocido por sus siglas en inglés CSSO), la Alianza Global para la Facilitación del Comercio (GATF), la Asociación Internacional de Transporte Aéreo (conocido por sus siglas en inglés como IATA) y el Centro de Comercio Internacional (conocido por sus siglas en inglés como ITC) a elaborar un Repositorio de Facilitación del Comercio COVID-19 en el que se consoliden todas estas acciones. Se puede acceder al Repositorio de Facilitación del Comercio COVID19 a través del siguiente enlace https://www.tfafacility.org/covid19trade-facilitation y se actualiza periódicamente para reflejar el nuevo material de orientación desarrollado.

\subsection{Administración Aduanera de Honduras ante el COVID-19}

Ante la declaración de pandemia por parte de la OMS; la administración de aduanas del país comunica el 12 de marzo que las actividades seguirían normalmente en las aduanas, en las actividades de comercio exterior de importación y exportación de mercancías. En donde se instruye la agilización para el ingreso de insumos de higiene, limpieza y equipo médico que sería utilizado en la prevención del COVID-19. Sin embargo, los empleados y todos aquellos que pertenezcan a los miembros necesarios de la cadena logística, deberán solicitar la constancia para la circulación y así poder identificarlos de acuerdo a su número de registro para lo cual la Administración Aduanera de Honduras puso a su disposición la plataforma http://sarah.dara. gob.hn:8082/sarah en donde se realizó el proceso de solicitud para la circulación.

Se establece que todo Auxiliar de la Función Pública Aduanera que se encuentre operando durante la vigencia del Decreto Ejecutivo PCM-021-2020 deberá de portar la constancia impresa o en digital extendida por esta Administración, asimismo tarjeta de identidad personal para validación de las autoridades competentes.

En este tiempo el 13 de marzo a través del Decreto 31-2020 se autoriza a las empresas acogidas a los regímenes especiales a donar o vender el 100\% 
de su producción dentro del territorio nacional a las instituciones del sector público, tales como los insumos y equipos médicos para el tratamiento actual de la pandemia siempre que sea necesario atender la emergencia sanitaria.

E1 14 de marzo se comunica que el Gobierno de la República de Honduras a través de la Administración Aduanera de Honduras en conjunto con la República de El Salvador mediante la Dirección General de Aduanas del Ministerio de Hacienda ante la presencia del COVID-19 acordaron diferentes medidas con respecto al tránsito de mercancías por las fronteras de ambos países con la finalidad de agilizar el comercio de las mercancías entre ambas repúblicas.

Aunque el 16 de marzo el Gobierno de Honduras declaraba toque de queda las operaciones aduaneras estaban fuera de esta disposición debido a que en el artículo 4 de las excepciones a la circulación de funcionarios, inciso 2) Se exceptúan de esta medida al personal incorporado para atender la emergencia nacional, altos funcionarios, personal de salud, socorro, seguridad y defensa nacional, la Dirección de Protección al Consumidor, personal de aduanas, migración, puertos y aeropuertos $\mathrm{u}$ otro servicio público indispensable (Poder Ejecutivo de Honduras, 2020). El 24 de marzo la administración de aduanas del país establece un protocolo de contingencia ante la emergencia nacional por COVID-19 mediante la certificación SG-059-2020 con la finalidad facilitar y dar continuidad a todo el proceso administrativo aduanero. Igualmente se declararon inhábiles plazos, actuaciones y términos legales que establece la ley.

Mediante ese mismo certificado la Administración Aduanera de Honduras se compromete a garantizar que durante el estado de emergencia nacional las aduanas del país seguirían habilitadas de manera ininterrumpida con la tramitación ordinaria que permita sostener la actividad económica. Igualmente se solicita a la Dirección Nacional de Estrategia Financiera y Administrativa que a través de la Gerencia Administrativa preste la colaboración y logística necesaria para el traslado de los empleados a las aduanas, se instruye a limitar la presencia física a una cantidad de personas determinadas debiendo cumplir con todas las medidas de bioseguridad establecidas, los colaboradores que deban presentarse a su área de trabajo deberán portar el debido carné y exhibirlo en un lugar visible, así como también su equipo de seguridad personal obligatorio ante la contingencia.

En cuanto al tránsito aduanero se insta a garantizar el mismo en los puntos de entrada y las inspecciones fronterizas dando la debida prioridad a los insumos de primera necesidad se flexibiliza el despacho aduanero en aplicación de las medidas de contingencia establecidas, entre otras disposiciones (Administración Aduanera de Hondras, 2020).

\subsubsection{Plan de medidas preventivas para mantener la recaudación aduanera}

El 24 de marzo la Administración Aduanera de Honduras establece un plan y medidas adoptadas para la gestión de la crisis sanitaria ante COVID-19, el cual establece lo siguiente:

- Son medidas orientadas a la facilitación del comercio en insumos o productos que son necesarios para mitigar la emergencia $y$ desabastecimiento de alimentos.

- La Administración Aduanera de Honduras se encargará del traslado de empleados a las aduanas marítimas, aéreas y terrestres. Todos deberán aplicar el Protocolo de Seguridad e Higiene sobre las medidas de prevención del COVID-19 (utilizar mascarillas, guantes, gel, etc.).

- Se solicita la colaboración para que le personal de aduanas pueda circular o movilizarse hasta sus áreas de trabajo, entre estos incluye agentes aduaneros, consolidadores, agencias navieras, depositarios, líneas aéreas, courier y transportistas de carga, que se trasladen a las aduanas y depósitos.

- En el despacho aduanero la declaración seguirá siendo presentada de manera electrónica, la Declaración Única Centroamericana (DUCA) solamente será presentada de manera electrónica y el análisis de riesgo se mantiene de acuerdo con los tres tipos de canales ya conocidos.

- Todas las mercancías deberán cumplir con las medidas establecidas por el Servicio Nacional de 
Sanidad e Inocuidad Agroalimentaria (SENASA), la Agencia de Regulación Sanitaria (ARSA) y la Organización Internacional Regional de Sanidad Agropecuaria (OIRSA).

- Se prioriza los despachos de todas las mercancías de primera necesidad, medicamentos, equipo médico y quirúrgico, insumos y materiales de protección y bioseguridad, productos sanitarios, $\mathrm{y}$ materias primas para atender la Declaratoria de Emergencia.

- Se les solicita a los Auxiliares de la Función Pública Aduanera (navieros, aéreos, agentes de carga y consolidadores, courier) poner a disposición de sus usuarios la automatización y digitalización de trámites y documentos para optimizar el despacho aduanero; e implementar métodos electrónicos de consulta de carga y facturación electrónica.

- En cuanto a los transportistas y conductores de carga internacional deben sujetarse a los protocolos de seguridad. Si se detecta un conductor con síntomas sospechosos de COVID-19 la autoridad aduanera debe proceder a lo siguiente:

- Permitir que el conductor estacione el medio de transporte y gestionar el cambio de conductor, previa fumigación y esterilización del medio

- Permitir la rectificación de la Declaración Única Centroamericana (DUCA) dejando constancia en la casilla de Observaciones.

- Se autorizó el uso de un pagaré en caso de que no se pueda gestionar previamente un Depósito en Garantía, el cual debe reunir todos los requisitos señalados en el artículo 590 del Código de Comercio. Para los casos de empresas acogidas al Régimen de Importación Temporal (RIT) y demás regímenes de admisión temporal. También, se autoriza el uso de pagarés. Los pagarés darán lugar a la emisión del documento de Autorización de Levante.

- Una vez declarado la finalización del estado de emergencias se realizará una evaluación del impacto y se elaborará un plan de recuperación del servicio aduanero, el cual debe incluir revisión de los oficiales aduaneros que pudieron haber sido expuestos a contaminación y diseñar e implementar un programa de auditoría para mitigar los riesgos de abusos de beneficios concedidos durante la emergencia.

\subsubsection{Otras disposiciones concernientes a la contingencia COVID-19}

E1 03 de abril se establece la prohibición de exportación de frijol rojo correspondientes a los incisos arancelarios 0713.32.00.00 y 0713.33.40.00 del Arancel de Centroamericano, estos podrán ser exportados nuevamente hasta que termine el estado de emergencia, todo con la finalidad de evitar un desabastecimiento en el mercado local de los alimentos básicos de la población (Administracion Aduanera de Honduras, 2020).

E1 05 de abril la Administración de Aduanas anuncia que durante el periodo de semana santa se estaría trabajando con normalidad y permanencia en todas las diferentes aduanas del país. Ese mismo día el Sistema Nacional de Gestión de Riesgos (SINAGER) autorizo la circulación a nivel nacional del servicio de transporte de carga, mercancías y vehículos de importación entre otros.

A través de la Certificación SG-064-2020 la Administración Aduanera de Honduras (2020), acuerda aprobar el procedimiento para la facilitación del despacho aduanero de mercancías en las empresas acogidas a los diferentes regímenes especiales en la nacionalización de: insumos, materias primas, material de empaque y envase, productos sanitizantes y medicamentos para atender la emergencia sanitaria, y el equipo médico específico para el tratamiento de la pandemia la certificación establece las medidas a tomar de acuerdo al régimen especial al que se ampare.

E1 21 de abril la Administración Aduanera de Honduras (2020) establece mediante Certificación SG-065-2020 que el plazo de suspensión de labores permanece del 20 al 25 de abril en donde los empleados de la administración aduanera permanecerán en casa y estarán sometidos lo establecido por SINAGER con excepción de aquellos colaboradores que deban desplazarse hasta las diferentes aduanas del país los cuales deberán aplicar el protocolo de seguridad correspondiente. Igualmente se pone a la disposición el correo electrónico cespinal@aduanas.gob.hn con la finalidad de recibir todas las solicitudes correspondientes de parte de los apoderados legales y 
obligados tributarios. Se continúa la suspensión de los plazos, actuaciones y términos legales que establece la ley esta suspensión no es aplicable a los plazos de la notificación de las resoluciones emitidas por la administración aduanera.

A partir del 30 de abril la Constancia de Autorización para la Circulación de los Auxiliares de la Función Pública Aduanera que emite la Administración Aduanera de Honduras el proceso de anulación, incremento o modificación del personal que cada empresa ha estipulado para movilizarse y realizar los trámites correspondientes a la misma; ya no se podrá realizar. Debido a que se manifestaron ciertas irregularidades como falsificaciones o alteraciones en los documentos, igualmente se les aconseja que el uso de dicha constancia sea meramente para gestiones aduaneras.

En los casos en los que se hayan incurrido a falsificaciones y alteraciones la administración explica que remite al Ministerio Publico para su investigación y proceso.

La situación al 11 de mayo seguía con normalidad en todas las aduanas del país a excepción de la aduana del Florido, la cual se mantenía en un cierre temporal de las operaciones por la detección de un caso positivo por COVID-19 de una delegada de salud. Por lo que, se procedió a realizar todo el proceso de desinfección de la aduana de acuerdo con lo establecido por la SINAGER. Hasta este entonces se reportaban 3 casos positivos de COVID-19 en los colaboradores del sector público de la Administración Aduanera del país. Esto dio lugar a un reforzamiento de las medidas de seguridad adoptadas en todas las aduanas del país. E1 12 de mayo el Florido vuelve a sus labores con estrictas medidas de bioseguridad esta reapertura se realizó tras la aprobación de las autoridades de SINAGER.

\subsubsection{Declaración de mercancias en forma anticipada}

Transmitir de manera anticipada la declaración de mercancías es un tema que ha venido ejecutándose con la finalidad de agilizar el comercio, permitiendo la reducción de tiempos en la nacionalización de las mercancías en el lugar de arribo. Las mercancías deben ser declaradas antes que el medio de transporte toque el territorio nacional este tipo de procedimientos son avalados por la OMA desde 1999 en el Convenio de Kioto.

El último comunicado de la Administración Aduanera de Honduras (2020) con respecto a la declaración de mercancías de forma anticipada establece a través de la disposición administrativa aduanas DNOA-422020 del 08 de abril del 2020 que a partir del 11 de mayo del 2020 para los regímenes de importación definitiva 4000 y régimen de tránsito interno de aduanas con código 8000, así como el tránsito interno de aduana a Zona Libre con código 8100 serán de forma obligatoria y dentro del marco de la Unión Aduanera e Integración Profunda entre las repúblicas de Honduras y Guatemala para todos los regímenes aduaneros igualmente será obligatoria desde el 04 de mayo del 2020.

Esta presentación anticipada en tiempos de emergencia podría beneficiar en la agilización de los trámites debido a que se podrá decidir si es necesario reconocer las mercancías de acuerdo con la información proporcionada la cual se realizaría de manera electrónica. Siendo una solución efectiva para evitar los retrasos en los despachos aduaneros.

\section{METOdologia Y FUENTES DE DATOS}

\subsection{Alcance}

De acuerdo con la naturaleza de la investigación se realizó en base a un enfoque cualitativo, no experimental de corte transversal y descriptiva, donde se realizó la recopilación de datos no numéricos. Permitiendo mostrar la situación actual de las Administraciones de Aduanas y las disposiciones que se establecen a nivel internacional y nacional.

\subsection{Población y muestra}

El tipo de muestreo no probabilístico de casos críticos, en donde se han seleccionado los individuos que se encontraron a la disposición y dentro de la situación objeto de estudio. Haciendo hincapié a la referencia lógica para el resto de la población. 
Dentro de la población objetivo se encontraron dos subgrupos del sistema aduanero, conformado por el servicio aduanero de Honduras; el cual cuenta con 1,097 colaboradores, de estos, sin embargo, no se posee un número exacto dedicado únicamente a la labor aduanera debido a que este número engloba todas las áreas y departamentos de la institución en esta área pública se logró llegar a 32 encuestados.

El otro sector que lo conforma son los Auxiliares de la Función Pública Aduanera de los cuales se han elegido a los Agentes Aduaneros quienes a nivel de país se encuentran un total de 260 según datos de la Federación Nacional de Agentes Aduanales de Honduras (FENADUANAH). Que de acuerdo un $90 \%$ de confianza y un $10 \%$ de margen de error nuestra muestra es de 54 Agentes Aduaneros de los cuales se lograron validar 49 encuestados.

Por lo que tenemos un total de 81 encuestados correspondientes el $60.5 \%$ al sector privado y el $39.5 \%$ del sector público.

\subsection{Recolección de datos}

La recopilación de datos se realizó entre la séptima y octava semana de cuarentena del 28 de abril al 05 de mayo a través de medios electrónicos de creación de formularios que nos permitió llegar a cada uno de los encuestados. La encuesta se aplicó con el objetivo de indagar sobre la forma en cómo las aduanas del país se encuentran realizando las gestiones aduaneras relacionado a la bioseguridad ante la pandemia. Se logró tener conversaciones con algunos de los encuestados lo cual nos ayudó a establecer de forma más asertiva la información relacionada con la situación vivida actualmente.

\section{RESULTADOS Y DISCUSIONES}

\subsection{La actividad laboral en el Sistema Aduanero ante el COVID-19}

La actividad laboral en las aduanas del país no ha cesado en ningún momento con ciertas excepciones de la aduana El Florido la cual cerró sus instalaciones por un periodo de 48 horas. El 100\% han establecido que no han dejado sus actividades laborales las cuales han continuado ya sea a través del teletrabajo o presentándose al lugar laboral de forma diaria o en turnos.

E1 53.1\% han cumplido con sus labores a través del teletrabajo definido como la prestación de servicios de carácter no presencial fuera de las instalaciones del patrono en virtud de la cual un trabajador puede desarrollar su jornada laboral desde su propio domicilio centro que se destine para tal fin o en trabajos de campo mediante el uso de medios telemáticos. (Ministerio de Salud de Costa Rica. , 2020).

Figura 1 Formas en cómo ha realizado su trabajo en tiempos de cuarentena.

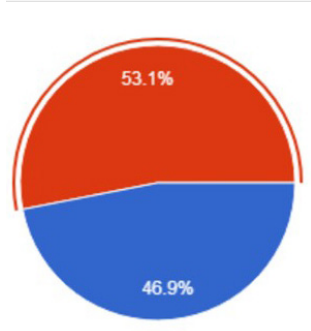

Movilizándome hasta mi puesto de trabajo.

- A través del teletrabajo (Trabajo que una persona realiza para una empresa desde un lugar alejado de la sede de esta (habitualmente su propio domicilio), por medio de un sistema de telecomunicación.)

Fuente: Elaboración propia.

Muchos han tenido que movilizarse hacia sus puestos de trabajo debido a que el comercio no puede parar para que cada una de las familias tengan los insumos necesarios, tal y como lo han declarado la OMA y las Administraciones Aduaneras del país.

\subsection{Opinión conforme las medidas de bioseguridad adoptadas}

En toda área laboral actualmente se deben tomar todas las medidas de bioseguridad necesarias con el fin de salvaguardar la integridad y salud de las personas. Conforme a ello se les ha preguntado a los encuestados si en su área de trabajo están tomando medidas de bioseguridad para protegerse de la actual pandemia. 
Figura 2 Se han tomado medidas de seguridad en su área laboral

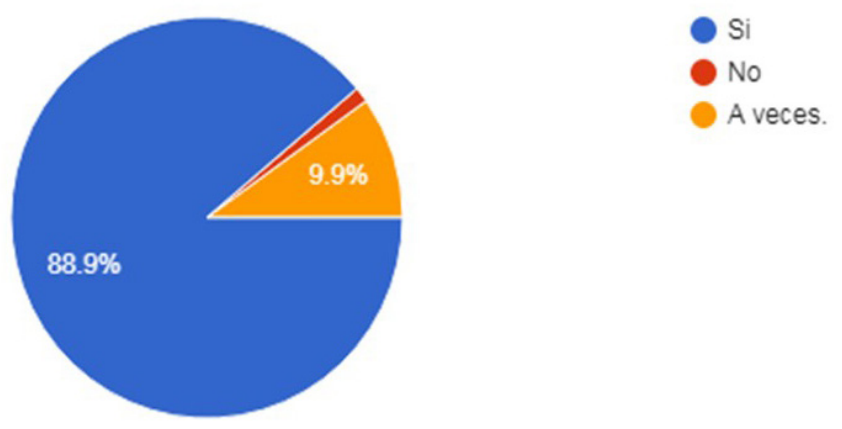

Fuente: Elaboración propia.

Según los resultados el $88.9 \%$ indican que en su área de trabajo sí se están aplicando las medidas de bioseguridad. Igualmente, es algo sorprendente notificar que, aunque solamente sea un $1.2 \%$ de los encuestados que establecen no utilizar medidas de bioseguridad ese porcentaje podría representar un nivel de propagación como ya lo hemos visto en otros casos.

Figura 3 Las medidas de bioseguridad son adoptadas en el puesto laboral son adecuadas, para hacerle frente al COVID-19
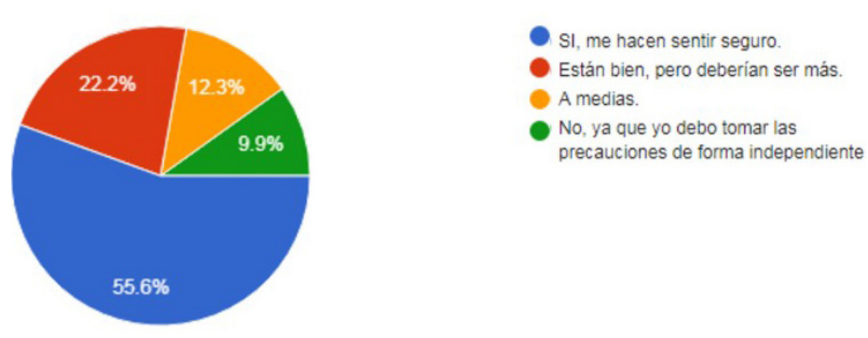

Fuente: Elaboración propia.

Igualmente, se ha cuestionado sílas medidas adoptadas para prevenir el contagio son las adecuadas. E1 55.6\% de ellos establecen sentirse seguros con estas medidas mientras que la contraparte de la muestra indica un malestar, el $22.2 \%$ considera que deberían ser más, el $12.3 \%$ que son a medias, y el $9.9 \%$ que ellos mismos son los que deben tomar las precauciones al respecto.
Las medidas de seguridad que han adoptado son el uso de mascarillas, gel antibacterial, guantes son los más utilizados. Entre otras medidas tomadas son el distanciamiento, desinfección con sustancias como cloro o productos comerciales tipo Lysol en la entrada de la oficina, desinfección de todas las áreas de la oficina, así como también de los vehículos. En algunos casos, usos de botas desechables, uso de termómetro infrarrojo para control de temperatura, uso de máscaras protectoras, trajes de bioseguridad, lentes protectores, gorro y lavado constante de manos.

Por la situación de paralización de los medios de transporte público se les ha proporcionado medio de transporte exclusivo recordando que esta medida es parte del plan establecido.

Figura 4 Se ha afectado el estado de ánimo y la forma en cómo realizas el trabajo, como consecuencia de la pandemia.

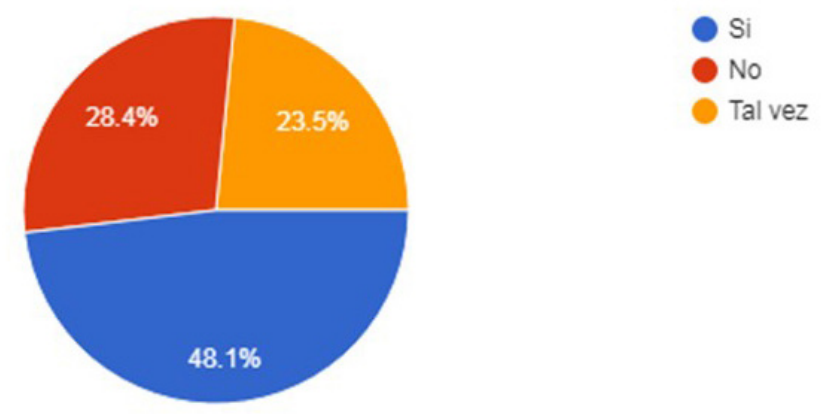

Fuente: Elaboración propia.

Esta situación ha afectado al mundo en general ya sea desde el punto económico como desde la situación emocional. Observamos que el $48.1 \%$ se ha visto afectado en su estado de ánimo los cuales han expresado que en muchas ocasiones los niveles de estrés han aumentado por el temor al contagio al estar más expuestos.

Como lo vemos en la figura 5 casi el $66 \%$ de los encuestados se han sentido inseguros en sus puestos de trabajo generando incertidumbre ante cualquier síntoma que se percate, sabiendo que, aunque este no est relacionado al virus actual el temor de haberse infectado es aún mayor. Muchos han sido 
estigmatizados por encontrarse al pie del trabajo como lo vemos en casos de personas contagiadas confirmadas y esto ha aumentado aún más con la confirmación de casos positivos de COVID-19 en la aduana del Florido.

Figura 5 Mantienes un sentimiento de inseguridad al estar en el puesto de trabajo, como consecuencia de la pandemia.

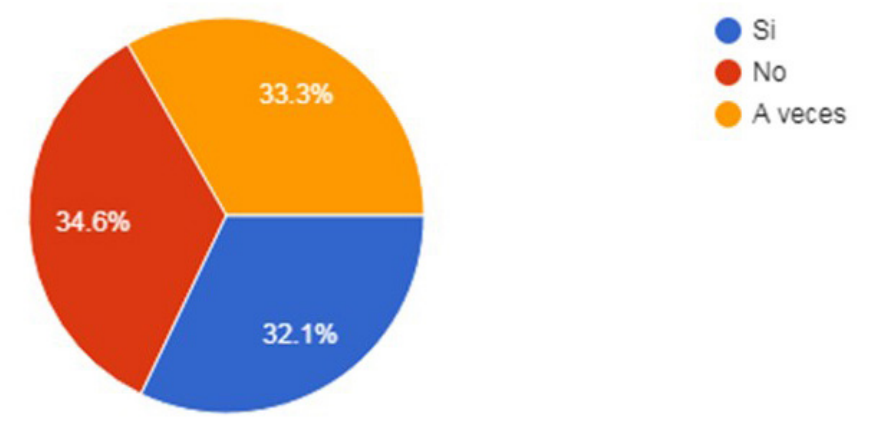

Fuente: Elaboración propia.

El personal de aduanas tanto público como privado ha sido afectado en diversos factores gran parte del sector privado se ha visto afectado a nivel económico, ya sea por el bajo comercio de algunos productos o por la posible paralización de algunas actividades correspondientes a la cadena de suministro recordando que la prioridad de acuerdo con la OMA son los suministros de primera necesidad.

El estado emocional y físico se ve reprimido por la situación de casos de estrés que generan insomnio, ansiedad, depresión, entre otras. Así como, otros casos de salud que han sido desatendidos por la prioridad que ha tenido la emergencia actual como lo podemos observar en la figura 6.

\section{3. ¿Cómo han seguido funcionando las aduanas de} Honduras ante esta emergencia?

La actividad comercial no ha cesado y las aduanas no han parado sus labores en ningún momento. Sin embargo, el $61.7 \%$ de los encuestados han notado una disminución en la actividad comercial conforme a la carga de trabajo que ellos han mantenido en situaciones normales el $23.5 \%$ considera que se ha mantenido y el $14.8 \%$ consideran que ha aumentado. En pláticas con algunos agentes aduaneros racionalmente expresan que han sido ellos quienes han tenido que realizar personalmente los trámites.

Figura 6 En que factor se ha visto afectado, ante la situación creada por el COVID-19

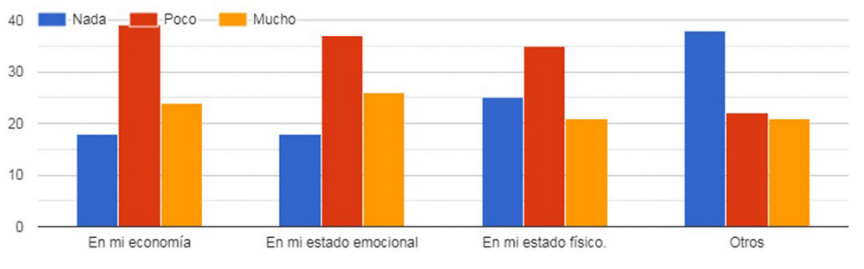

Fuente: Elaboración propia.

Figura 7 Han disminuido las actividades comerciales, en relación con la carga de trabajo normal; como consecuencia de la pandemia.

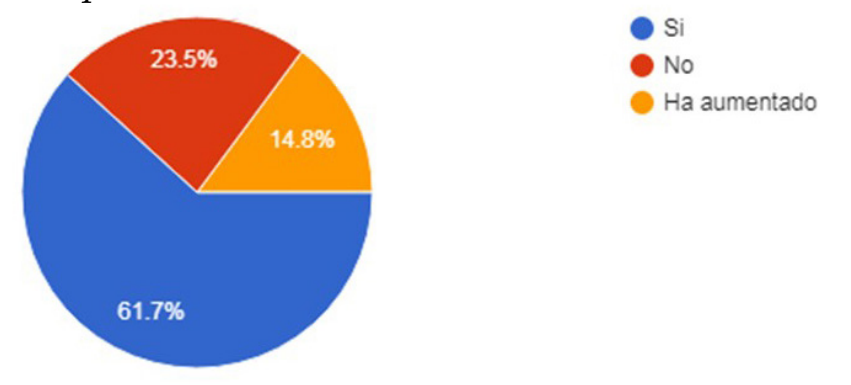

Fuente: Elaboración propia.

Aún con esta situación se considera que por parte del sector público la agilización de los tramites va de lo regular a normal con horarios de trabajo ordinarios o normales en donde se han laborado los días feriados. Existen diversos factores como poco personal debido a que están trabajando por turnos lo que ha ralentizado los procesos haciendo largo el proceso de despacho y así aumentando el gasto de almacenaje de mercancías con medidas de bioseguridad bajas en algunos casos, por lo que se recomienda su mejora dándole prioridad a la carga de alimentos o suministros médicos.

\subsection{La declaración de mercancías de forma anticipada}

En cuanto a la declaración anticipada de mercancías como vimos anteriormente esté es un mecanismo que viene a facilitar el comercio y ante una situación de crisis la simplificación de procesos ayuda a que sean más eficientes y eficaces cumpliendo objetivos como 
la disminución de tiempos y costos de entrega de mercancías.

Figura 8 Considera que la declaración anticipada de mercancias agilizara las operaciones de despacho, siendo un medio efectivo ante la pandemia.

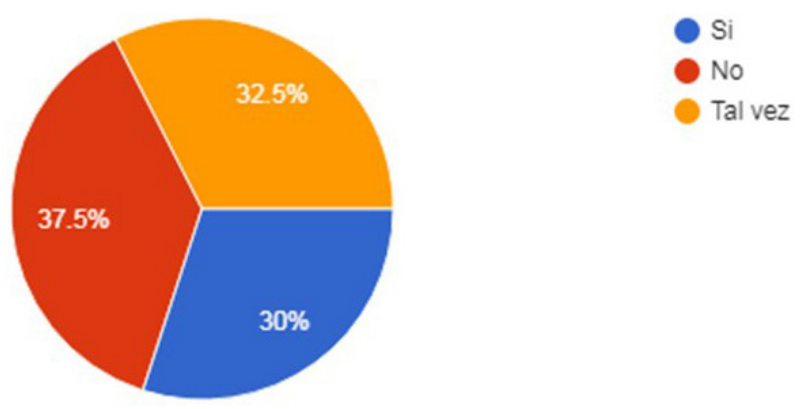

Fuente: Elaboración propia.

Conforme a esta herramienta ahora obligatoria el 30\% opina que presentar la declaración de forma anticipada si ha agilizado las operaciones de despacho. Sin embargo, el 37.5\% un número considerable establece que no, ya que aún los procedimientos han sido lentos.

\section{CONCLUSIONES Y RECOMENDACIONES}

\subsection{Conclusiones}

Desde la OMA y todas las Organizaciones Internacionales relacionadas con el comercio de mercancías vemos la imperiosa necesidad de crear mecanismo para la facilitación del comercio. Se han dado diversos acercamientos que pretenden crear una simplificación de procesos, esto a través de las recomendaciones que los países realicen debido a sus buenas prácticas, ante la pandemia vivida.

La situación actual es un punto de entrada para todas aquellas personas que ante una situación de emergencia han querido sacar un provecho de este dándose diversidad de falsificaciones en suministros médicos de protección y de higiene en los cuales el comercio ha aumentado.

E1 trabajo desde casa ha sido una forma de escape ante la situación de confinamiento. Sin embargo, en el ámbito de aduanas no se puede realizar al 100\% a través de esta forma remota. Las herramientas tecnológicas permiten la transferencia de datos electrónicamente y de manera segura pero las revisiones y los despachos de las mercancías ameritan la presencia del personal en las aduanas.

Esta situación conlleva a la necesidad de adoptar todas las medidas de seguridad. Sin embargo, vemos como un $9.9 \%$ solo las utilizan a veces y un $1.2 \%$ no las utilizan; igualmente este $9.9 \%$ establece que ellos mismos deben comprar sus equipos de protección para estar seguros. Creando un estado crítico para los compañeros de trabajo y personas que se encuentren alrededor debiendo recordar que debemos evitar la estigmatización, pero tomando las medidas correspondientes.

Las personas en este rubro también se han visto afectadas tanto en su factor económico como físico y mental. Afectando la forma en cómo ellos ejercen su trabajo en donde el $48.1 \%$ lo ha percibido de esa forma sintiéndose inseguros en sus puestos de trabajo.

Las actividades comerciales desde el punto de vista de las aduanas el $61.7 \%$ considera que han disminuido las actividades y se han ralentizado debido a los turnos que se han asignado. Por lo que, no está todo el personal disponible y en busca de la facilitación del comercio la Administración Aduanera implementa herramientas como la declaración de mercancías de forma anticipada lo que el $30 \%$ dice que sí y el 32.5\% que tal vez pueden agilizar los procesos de despacho de mercancía.

Concluimos que la administración aduanera es un campo muy importante que ha venido a garantizar el abastecimiento de los insumos necesarios para todas las familias del país. Mantener el comercio vivo y en marcha permite que la situación en estado de crisis sea más amigable para cada uno de los habitantes; el priorizar y agilizar el comercio de todo lo necesario ha sido el lema desde máxima organización hasta cada una de las administraciones aduaneras del país. 


\subsection{Recomendaciones}

De acuerdo con los hallazgos obtenidos y en base a la información recopilada a nivel internacional y nacional se recomienda:

- Implementar y socializar el repositorio de recomendaciones establecidas por las partes interesadas a través de los medios oficiales de la OMA.

- Implementar y socializar las herramientas que la OMA pone a la disposición del público en general, así como también buscar de forma inmediata la traducción oficial de los documentos.

- Mantener alerta las aduanas del país ante las posibles falsificaciones de suministros.

- Socializar el plan de medidas preventivas para mantener la recaudación aduanera.

- Crear medios de comunicación electrónica seguras donde la transmisión de datos no de paso a virus, malware o phishing.

- Los colaboradores deberán tener a la disposición por parte de la institución o empresa todos los equipos de protección personal y medidas necesarias para combatir y prevenir el contagio del COVID-19.

- Mantener un liderazgo en la seguridad y salud ocupacional debiendo incentivar a todos los colaboradores a mantener el uso constante de todos los equipos de protección personal y de desinfección de áreas disponibles.

- Proporcionar atención psicológica que garantice el anonimato a las personas que se sientan emocionalmente afectadas e indagar como solucionar los atrasos que generan gastos para que el nivel económico no sea totalmente impactado.

- Socialización y/o capacitación de los procedimientos aduaneros para que no existan atrasos en los despachos de mercancías.

\section{REFERENCIAS}

Administración Aduanera de Honduras. (24 de Marzo de 2020). Certificación No Aduanas -SG-0592020. SG-059-2020. Tegucigalpa, Distrito Central, Honduras: Recuperado el 28 de abril en https:// www.aduanas.gob.hn/wp-content/uploads/2020/03/
CERTIFICACION-ADUANAS-SG-059-2020. pdf.

Administración Aduanera de Honduras. (07 de abril de 2020). Certificación ADUANAS-SG-064-2020. Tegucigalpa, Honduras: Recuperado el 28 de abril en https://www.aduanas.gob.hn/8020-2/.

Administración Aduanera de Honduras. (21 de abril de 2020). Certificación ADUANAS-SG-065-2020. Tegucigalpa, Francisco Morazán, Honduras: Recuperado el 28 de abril en https://www. aduanas.gob.hn/wp-content/uploads/2020/04/ C E R T I F I C A C I O N - N O - A D U A N A S SG-065-2020.pdf.

Administración Aduanera de Honduras. (08 de abril de 2020). Disposición Administrativa Aduanas DNOA42-2020. Tegucigalpa, Francisco Morazán, Honduras: Recuperado el 28 de abril en https://www.aduanas. gob.hn/declaracion-anticipada-de-mercancias-2/.

Administracion Aduanera de Honduras. (03 de Abril de 2020). DISPOSICIÓN ADMINISTRATIVA ADUANAS-DNOA-43-2020. Probibir la exportacion de frijoles segun acuerdo 028-2020. Tegucigalpa, Francisco Morazan, Honduras: Recuperado el 28 de abril en https://www.aduanas.gob.hn/disposicionadministrativa-aduanas-dnoa-43-2020/.

CNN en Español. (20 de Febrero de 2020). Cronología del coronavirus: así comenzó y se extendió el virus que tiene en alerta al mundo. Obtenido de Recuperado el 28 de abril en https://cnnespanol.cnn.com/2020/02/20/ cronologia-del-coronavirus-asi-comenzo-y-seextendio-el-virus-que-pone-en-alerta-al-mundo/

Ministerio de Salud de Costa Rica. . (2020). ¿Que es el teletrabajo? . Obtenido de https://www. ministeriodesalud.go.cr/index.php/teletrabajo/quees-teletrabajo.

Poder Ejecutivo de Honduras. (2020). Decreto Ejecutivo Número PCM-021-2020. Tegucigalpa: Honduras: Diario La Gaceta No 35201. 
World Customs Organization. (25 de Marzo de 2020). COVID-19: WCO launches an IPR CENcomm Group for data exchange on counterfeit medical supplies and fake medicines. Obtenido de http://www.wcoomd. org/en.aspx: http://www.wcoomd.org/en/media/ newsroom/2020/march/covid_19--wco-launches-anipr-cencomm-group.aspx

World Customs Organization. (06 de Abril de 2020). Declaración conjunta de la OMA y la OMC sobre las medidas comerciales relacionadas con COVID-19. Obtenido de http://www.wcoomd.org/en.aspx: http:// www.wcoomd.org/en/media/newsroom/2020/april/ wco-wto-joint-statement-on-covid-19-related-trademeasures.aspx

World Customs Organization. (21 de abril de 2020). La OMA y la UPU toman medidas para facilitar el intercambio de información sobre la cadena de suministro postal mundial a raíz de la pandemia de COVID-19. Obtenido de http://www.wcoomd.org/en.aspx: http:// www.wcoomd.org/en/media/newsroom/2020/april/ wco-an

World Customs Organizations. (20 de marzo de 2020). La comunidad aduanera global moviliza esfuerzos para mitigar los efectos de la pandemia COVID-19. Obtenido de http://www.wcoomd.org/en.aspx: http://www. wcoomd.org/en/media/newsroom $/ 2020 / \mathrm{march} /$ theglobal-customs-community-mobilizes-efforts-tomitigate-the-effects-of-the-covid-19-pandemic.aspx 


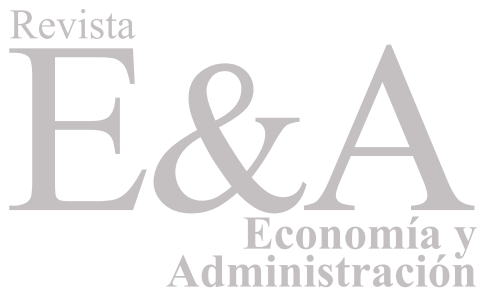

